\title{
Endovascular stent graft placement in patients with type $B$ aortic dissection: A meta-analysis in China
}

\author{
Jiang Xiong, PhD, MD, ${ }^{a}$ Bo Jiang, PhD, ${ }^{b}$ Wei Guo, MD, ${ }^{\text {a }}$ Shen-Ming Wang, PhD, MD, FACS, ${ }^{\mathrm{c}}$ and \\ Xin-Yuan Tong, $\mathrm{BM}^{\mathrm{d}}$
}

Objective: We summarized all published studies for endovascular stent graft placement among patients with type $\mathrm{B}$ aortic dissection in China with respect to clinical success, complications, and outcomes.

\begin{abstract}
Methods: A meta-analysis was performed on all published studies of retrograde endovascular stent graft placement encompassing 3 or more patients with type B aortic dissection. Thirty-nine studies, involving a total of 1304 patients from January 2001 to December 2007, were included.
\end{abstract}

Results: The average patient age was 52 years. Procedural success was reported in $99.2 \% \pm 0.1 \%$ of patients. Major complications were reported in $3.4 \% \pm 0.1 \%$ patients, with the most severe neurologic complications in $0.6 \%$. Periprocedural stroke was encountered more frequently than paraplegia $(0.2 \%$ vs $0 \%)$. The overall 30 -day mortality was $2.6 \% \pm 0.1 \%$. In addition, $1.5 \% \pm 0.1 \%$ of patients died over a mean follow-up period of $27.1 \pm$ 17.5 months. Life-table analysis yielded overall survival rates of $96.9 \%$ at 30 days, $96.7 \%$ at 6 months, $96.4 \%$ at 1 year, $95.6 \%$ at 2 years, and $95.2 \%$ at 5 years.

Conclusion: Although therapy with traditional medicines still remains the first line of treatment for type B aortic dissection, endovascular stent graft placement has shown its advantages, with a success rate of $99 \%$ or greater in a select cohort. The technical survival rate, major complications, and acute and midterm survival rates in the Chinese-language literature appeared to favorably compare with that seen in published literature. This analysis is the first to provide an overview of the currently available literature on endovascular stent graft placement in type B aortic dissection in China.

\section{Supplemental material is available online.}

A growing body of evidence has demonstrated the efficacy of endovascular repair for aortic dissection (AD). However, long-term studies on whether endovascular stent graft placement is the optimal initial treatment for elective cases of type B AD remain inconclusive. ${ }^{1}$ Eggebrecht and colleagues ${ }^{2}$ and Resch and associates, ${ }^{3}$ respectively, reported multicenter retrospective studies of endovascular stent graft placement in patients with type B AD. However, the data were extracted exclusively from the English-language medical literature and mostly represented Western countries, such as those in Europe and North America. In 1998, endovascular stent graft

\footnotetext{
From the Department of Vascular Surgery, Clinical Division of Surgery, ${ }^{a}$ Chinese PLA General Hospital, Beijing, China; the Division of Cardiology, ${ }^{\mathrm{b}}$ University of Washington, Seattle, Wash; the Department of Vascular Surgery, ${ }^{\mathrm{c}}$ Institute of Vascular Surgery, The First Affiliated Hospital, Sun Yet-sen University, Guangzhou, China; and the Department of Statistics, ${ }^{\mathrm{d}}$ Chinese PLA General Hospital, Beijing, China

Received for publication June 3, 2008; revisions received Dec 23, 2008; accepted for publication Feb 2, 2009; available ahead of print April 9, 2009.

Address for reprints: Jiang Xiong, PhD, MD, Department of Vascular Surgery, Institute of Vascular Surgery, Chinese PLA General Hospital, 28 Fuxing Road, Beijing, China PR, 100852 (E-mail: xiongjiangdoc@126.com)

J Thorac Cardiovasc Surg 2009;138:865-72

$0022-5223 / \$ 36.00$

Copyright (c) 2009 by The American Association for Thoracic Surgery

doi:10.1016/j.jtcvs.2009.02.005
}

placement was introduced as a novel and less invasive option for patients with type $\mathrm{B} A \mathrm{AD}$ in China, and since then, more than 1300 patients with type B AD have opted for the treatment. To date, nearly all single-center studies of endovascular stent graft placement in patients with type $\mathrm{B} A \mathrm{AD}$ were published in the Chinese-language literature, with no multicenter analysis in China being reported.

The aim of this meta-analysis was to summarize all available published data with respect to clinical success, complications, and outcomes of endovascular stent graft placement among Chinese patients with type B AD. This Chinese multicenter report of endovascular stent graft placement in patients with type $\mathrm{B} A D$ will provide a direct comparison with existing studies. Most importantly, this study will provide an insight into the pattern of regional practice and patient distribution and demographic uniqueness.

\section{MATERIALS AND METHODS}

\section{Data Sources and Study Selection}

"Aorta," "dissection," and "stent", were used as the key words for a comprehensive search of both the English- and Chinese-language literature in the PubMed, MEDLINE, CBMdisc (Chinese Biomedical Database), and CNKI (Chinese National Knowledge Infrastructure) databases. All Chinese studies on endovascular stent graft treatment published between January 2001 and December 2007 were identified for further analysis. Several criteria were applied to determine whether articles would qualify for the analysis: (1) articles including patients with type B AD undergoing retrograde endovascular stent graft placement into the descending thoracic aorta were selected for data extraction; (2) articles reporting on antegrade, surgical ("open") stent graft placement through the aortic arch were not 


\section{Abbreviation and Acronym \\ $\mathrm{AD}=$ aortic dissection}

included; (3) a minimum series of 3 patients with type $\mathrm{B}$ AD treated with stent grafts was required for inclusion; and (4) case reports were not included. The selected articles were carefully reviewed, and data were extracted.

\section{Data Extraction and Statistical Analysis}

Each article was analyzed by using a standardized protocol according to the 53 predefined variables regarding clinical characteristics, procedural data, and in-hospital and long-term outcomes (see Table E1). Articles containing insufficient data $(<25 \%$ of predefined variables) were excluded from the data extraction. Only articles including patients with type B AD subjected to endovascular stent graft placement were included, and articles with patients with other thoracic aortic pathologies (eg, thoracic aortic aneurysms) were discarded. Unspecified information was classified as not available. As a result, the number of patients (denominator) varies, with the specific variables reported in the analysis.

Rates of events were calculated as the number of events divided by the number of treated patients with available data. The approach to calculating individual rates for different studies and to combining these rates into a weighted average produces identical results if the weights are defined as the proportion of available patients provided in a specific study. Results are presented as mean \pm standard error or median and range, where appropriate. No adjustment for multiple testing was applied because the statistical analysis was performed in an exploratory manner. Comparisons between patients in relation to publication date or in relation to operator's experience were made by using the 2sided Student's $t$ test for continuous variables. The life-table nonparametric method was used to generate estimates of survival at 30 days, 6 months, 1 year, 2 years, and 5 years. The Kaplan-Meier nonparametric method was used to generate estimates of 30-day mortality and 1-year survival in relation to publication date or in relation to operator's experience, and these values were compared by using the log-rank test. The 30-day procedure-related mortality of patients undergoing stent graft placement was compared with that of non-procedure-related mortality by using the log-rank test.

\section{Definitions}

$\mathrm{AD}$ was classified according to the Stanford classification. Dissection was considered an acute event if it occurred within the first 14 days from onset of symptoms, whereas it was considered chronic when occurring beyond 14 days. Complications were classified as major when life-threatening or prompting major therapeutic consequences (eg, access complications requiring surgical revision), whereas complications that did not require further treatment (eg, transient renal failure not requiring dialysis) were defined as minor. For the stent indication, Chinese vascular centers initially followed the indications for stent placement for type B dissection described by Nienaber and coworkers. ${ }^{4}$ However, with accumulating experience, some experienced centers extended indications 1,3 , and $7 .{ }^{4}$ Specifically, (1) when the distance from the entry site to the left subclavian artery is shorter than 1.5 $\mathrm{cm}$, endovascular repair was still made after a left carotid-subclavian artery bypass $^{5-7}$; (2) endovascular repair was also performed, even when the maximal aortic diameter was less than $5.5 \mathrm{~cm}^{5-7}$; and (3) when the bilateral iliac arteries were tortuous and stenosed, endovascular repair could be performed through the abdominal aorta. ${ }^{5-7}$ The technical details of endovascular repairs were described by Nienaber and colleagues. ${ }^{8}$ Procedural success was defined by the technically successful deployment of the endoprosthesis at the intended target location. Any death that occurred suddenly or could not be related to other causes was classified as being caused by aortic rupture. Reintervention was defined as the need for any surgical conversion or additional endovascular stent graft procedures. Procedure-related complica- tions refer to complications that are related to endovascular stent placement (eg, retrograde dissection, organ or peripheral artery malperfusion, dissection rupture, type I endoleak, and stroke for subclavian artery occlusion). Non-procedure-related complications indicate complications that are not related to endovascular stent placement (eg, myocardial infarction, cancer, and multiple organ failure or stroke with no relation to stent graft treatment). Studies were analyzed according to the reported total number of patients treated with endovascular stent graft placement, including dissections and other diseases of the thoracic aorta (eg, thoracic aortic aneurysms), to evaluate the potential influence of the operator's experience on outcomes. Centers with a published total number of patients beyond the median $(>16$ patients) were considered more experienced than those with total numbers below the median. In addition, the results of stent graft placement were analyzed in relation to the study publication date. Specifically, studies published between 2001 and 2004 represent the earlier experience, and those published between 2005 and 2007 are considered the latest experience.

\section{RESULTS \\ Study Selection}

A total of 70 Chinese-language publications published between January 2001 and December 2007 met the inclusion criteria. Twenty-three of these articles were excluded because of potential duplicate publications, and 7 publications were excluded for insufficient data. One study that incorporated complementary data from another study was also excluded for data extraction. Thirty-nine studies were eventually selected for data extraction and analysis. A total of 1359 patients who underwent endovascular stent graft repair of the thoracic aorta were included in this analysis. Of these patients, $1304(96.0 \%)$ had B-type AD (Table 1). ${ }^{5-7,9-45}$

\section{Patient Characteristics}

Seven hundred thirty-eight of 922 patients with available data had hypertension, and 130 of 696 patients with available data had cardiovascular risk factors, including 91 with coronary heart disease, 2 with aortic incompetence, and 37 with cardiac insufficiency (Table 2). Of note, 23 of 1139 patients had evidence of aortic rupture, as shown with computed tomographic angiography, magnetic resonance angiography, or digital subtraction angiography. For the grafts used in these studies, 726 grafts from 656 available cases were indicated, including Talent (Medtronic, Inc, Minneapolis, Minn; $\mathrm{n}=341$ ), Aegis (Microport, Inc, Shanghai, China; $\mathrm{n}=189$ ), Vasoflow (Weike Medical Apparatus and Instrument, Inc, Suzhou, China; $\mathrm{n}=18$ ), Endofit (Endomed, Inc, Phoenix, Ariz; $\mathrm{n}=15$ ), Zenith (Cook, Inc, Bloomington, Ind; $\mathrm{n}=$ 6), Powerlink (Endologix, Inc, Irvine, Calif; $n=2$ ), Aortec (YTH Biological Material Scitech, Inc, Beijing, China; $\mathrm{n}=$ 55), Griking (Grikin Advanced Materials, Inc, Beijing, China; $\mathrm{n}=36$ ), Ankura (Lifetech Scientific, Inc, Shenzhen, China; $n=15)$, and homemade grafts $(n=49)$.

\section{Procedural Data and In-Hospital Course}

The stent graft placement procedure was successful in $99.2 \% \pm 0.1 \%$ of patients (Table 3 ). Emergency surgical conversion was required in $0.7 \% \pm 0.1 \%$ of patients (Table 
TABLE 1. Detailed overview over the analysis reports

\begin{tabular}{|c|c|c|c|c|c|c|c|c|c|c|c|c|}
\hline Author & Year & $\begin{array}{c}\text { Patients with } \\
\text { type B AD } \\
\text { (n) }\end{array}$ & $\begin{array}{l}\text { Pro } \\
\text { success } \\
(\text { n) }\end{array}$ & $\begin{array}{l}\text { Emergency } \\
\text { conversion } \\
\text { (n) }\end{array}$ & $\begin{array}{c}\text { Overall } \\
\text { complications } \\
\text { (n) }\end{array}$ & $\begin{array}{c}\text { Major } \\
\text { complications } \\
\text { (n) }\end{array}$ & $\begin{array}{l}\text { Overall neurologic } \\
\text { complications } \\
\text { (n) }\end{array}$ & $\begin{array}{l}\text { Paraplegia } \\
\text { (n) }\end{array}$ & $\begin{array}{c}\text { 30-d } \\
\text { Mortality } \\
\text { (n) }\end{array}$ & $\begin{array}{c}\text { Late surgical } \\
\text { conversion } \\
\text { (n) }\end{array}$ & $\begin{array}{c}\text { Aortic rupture } \\
\text { during follow-up } \\
\text { (n) }\end{array}$ & $\begin{array}{c}\text { Late mortality } \\
\text { during follow-up } \\
\text { (n) }\end{array}$ \\
\hline $\mathrm{Shi}^{5}$ & 2005 & 150 & $150 / 150$ & 0 & 3 & 3 & 1 & 0 & 2 & 0 & 0 & 0 \\
\hline Guo $^{6}$ & 2005 & 159 & $159 / 159$ & 0 & 6 & 6 & 1 & 0 & 6 & 1 & 0 & 2 \\
\hline $\mathrm{Li}^{9}$ & 2001 & 5 & $3 / 4$ & 1 & 3 & 3 & 0 & 0 & 1 & 0 & 0 & 0 \\
\hline $\mathrm{Li}^{10}$ & 2002 & 20 & $19 / 20$ & 1 & 2 & 2 & 0 & 0 & 1 & NA & NA & NA \\
\hline Huang ${ }^{11}$ & 2002 & 6 & $6 / 6$ & 0 & 0 & 0 & 0 & 0 & 0 & 0 & 0 & 0 \\
\hline Wang $^{12}$ & 2003 & 18 & $16 / 18$ & 2 & 6 & 2 & 0 & 0 & 1 & NA & NA & NA \\
\hline Zhang $^{13}$ & 2003 & 10 & $8 / 10$ & 0 & 1 & 1 & 0 & 0 & 1 & 0 & 0 & 0 \\
\hline Zhang $^{14}$ & 2003 & 6 & $6 / 6$ & 0 & 0 & 0 & 0 & 0 & 0 & 0 & 0 & 0 \\
\hline $\mathrm{Shu}^{15}$ & 2004 & 19 & $19 / 19$ & 0 & 0 & 0 & 0 & 0 & 0 & 0 & 0 & 0 \\
\hline $\mathrm{Li}^{16}$ & 2004 & 11 & $11 / 11$ & 0 & 0 & 0 & 0 & 0 & 0 & NA & NA & NA \\
\hline $\mathrm{Wu}^{17}$ & 2004 & 15 & $15 / 15$ & 0 & 0 & 0 & 0 & 0 & 0 & 0 & 0 & 0 \\
\hline Wang $^{18}$ & 2004 & 5 & $5 / 5$ & 0 & 1 & 1 & 0 & 0 & 0 & 0 & 0 & 0 \\
\hline Yang ${ }^{19}$ & 2005 & 16 & $16 / 16$ & 0 & 1 & 0 & 0 & 0 & 0 & NA & NA & NA \\
\hline Jiang $^{20}$ & 2005 & 10 & $10 / 10$ & 0 & 1 & 1 & 0 & 0 & 1 & 0 & 0 & 0 \\
\hline $\mathrm{Su}^{21}$ & 2005 & 22 & $22 / 22$ & 0 & 1 & 1 & 0 & 0 & 1 & 0 & 0 & 0 \\
\hline $\operatorname{Lin}^{22}$ & 2005 & 26 & $26 / 26$ & 0 & 0 & 0 & 0 & 0 & 0 & 0 & 0 & 0 \\
\hline $\operatorname{Shan}^{23}$ & 2005 & 22 & $22 / 22$ & 0 & 1 & 1 & 0 & 0 & 1 & 1 & 0 & 0 \\
\hline $\mathrm{Bao}^{24}$ & 2005 & 7 & $7 / 7$ & 0 & 0 & 0 & 0 & 0 & 0 & 0 & 0 & 0 \\
\hline $\mathrm{Yu}^{25}$ & 2006 & 12 & $12 / 12$ & 0 & 0 & 0 & 0 & 0 & 0 & 0 & 0 & NA \\
\hline $\mathrm{Yu}^{26}$ & 2006 & 180 & $179 / 180$ & 1 & 2 & 2 & 0 & 0 & 2 & 0 & 1 & 1 \\
\hline $\mathrm{Xu}^{27}$ & 2006 & 76 & $76 / 76$ & 0 & 7 & 6 & 2 & 0 & 4 & 0 & 1 & 3 \\
\hline Wang $^{28}$ & 2006 & 12 & $12 / 12$ & 0 & 0 & 0 & 0 & 0 & 0 & 0 & 0 & 0 \\
\hline Luo $^{29}$ & 2006 & 22 & $21 / 22$ & 1 & 1 & 1 & 0 & 0 & 0 & 0 & 0 & 0 \\
\hline $\mathrm{Li}^{30}$ & 2006 & 17 & $17 / 17$ & 0 & NA & NA & NA & NA & 0 & 0 & 0 & 0 \\
\hline Adeliai $^{31}$ & 2006 & 23 & $22 / 22$ & 0 & 2 & 1 & 1 & 0 & 1 & 0 & 0 & 0 \\
\hline Zhang $^{32}$ & 2006 & 4 & $4 / 4$ & 0 & 0 & 0 & 0 & 0 & 0 & 0 & 0 & 0 \\
\hline Wang $^{33}$ & 2006 & 8 & $8 / 8$ & 0 & 0 & 0 & 0 & 0 & 0 & NA & NA & NA \\
\hline Luo $^{34}$ & 2006 & 55 & $55 / 55$ & 0 & 1 & 1 & 0 & 0 & 1 & 0 & 0 & 0 \\
\hline Zhaoo $^{35}$ & 2006 & 15 & $15 / 15$ & 0 & 0 & 0 & 0 & 0 & 0 & 0 & 0 & 0 \\
\hline Wang $^{36}$ & 2006 & 34 & $34 / 34$ & 0 & 2 & 2 & 0 & 0 & 2 & 0 & 0 & 0 \\
\hline $\operatorname{Tan}^{37}$ & 2006 & 15 & $15 / 15$ & 0 & 3 & 3 & 0 & 0 & 3 & 0 & 0 & 0 \\
\hline $\mathrm{Yu}^{38}$ & 2006 & 8 & $8 / 8$ & 0 & 0 & 0 & 0 & 0 & 0 & 0 & 0 & 1 \\
\hline $\mathrm{Li}^{39}$ & 2006 & 42 & $42 / 42$ & 0 & 0 & 0 & 0 & 0 & 0 & 0 & 0 & 0 \\
\hline $\mathrm{Mei}^{4{ }^{40}} \mathrm{Jing}^{7}$ & $\begin{array}{c}2007, \\
2003\end{array}$ & 146 & $143 / 145$ & 2 & 7 & 6 & 1 & 0 & 6 & 6 & 1 & 4 \\
\hline $\mathrm{Liu}^{41}$ & 2007 & 38 & $37 / 38$ & 1 & 1 & 1 & 0 & 0 & 0 & NA & NA & NA \\
\hline $\mathrm{Cao}^{42}$ & 2007 & 5 & $5 / 5$ & 0 & 0 & 0 & 0 & 0 & 0 & NA & NA & NA \\
\hline $\mathrm{Hu}^{43}$ & 2007 & 9 & $9 / 9$ & 0 & 1 & 0 & 0 & 0 & 0 & 0 & 1 & 1 \\
\hline Dong $^{44}$ & 2007 & 10 & $10 / 10$ & 0 & 0 & 0 & 0 & 0 & 0 & 0 & 0 & 0 \\
\hline Jing $^{45}$ & 2007 & 46 & $46 / 46$ & 0 & 4 & 0 & 2 & 0 & 0 & 0 & 1 & 3 \\
\hline All & & 1304 & $1290 / 1301(99.2 \%)$ & 9/1304 (0.7\%) & $57 / 1284(4.4 \%)$ & $44 / 1284(3.4 \%)$ & $8 / 1284(0.6 \%)$ & $0 / 1284(0 \%)$ & $34 / 1304(2.6 \%)$ & $8 / 1045(0.8 \%)$ & $5 / 1045(0.5 \%)$ & $15 / 1033(1.5 \%)$ \\
\hline
\end{tabular}

\section{ACD}


TABLE 2. Patient characteristics

\begin{tabular}{lcc}
\hline & $\begin{array}{c}\text { Data } \\
\text { available (n) }\end{array}$ & $\begin{array}{c}\text { No. of events } \\
\text { or cases }\end{array}$ \\
\hline Total no. of studies included & 39 & - \\
Total no. of patients reported & 1359 & - \\
No. of patients with type B AD & 1304 & $96 \%$ \\
No. of patients with type B AD & 39 & $16(4-180)^{*}$ \\
$\quad$ per study & 1296 & \\
Patient age (y) & 1277 & $1118(86.8 \% \pm 0.2 \%)$ \\
Male sex & 744 & $273(36.7 \% \pm 1.0 \%)$ \\
Acute dissection & 1139 & $23(2.0 \% \pm 0.2 \%)$ \\
Presenting with rupture & &
\end{tabular}

$A D$, Aortic dissection. *Median.

3), accounting for the total in-hospital conversion rate. Inhospital complications were reported in $4.4 \% \pm 0.2 \%$ of patients (Table 3). Complications were predominantly of major clinical significance $(3.4 \% \pm 0.1 \%)$, whereas minor complications were reported less frequently $(1.0 \% \pm$ $0.1 \%$ ). The most critical in-hospital complications were related to retrograde extension of the dissection into the ascending aorta $(0.4 \% \pm 0.0 \%)$ and neurologic complications $(0.6 \% \pm 0.0 \%)$. Concerning neurologic complications, periprocedural stroke occurred in $0.2 \% \pm 0.0 \%$ of patients, whereas no paraplegia was reported in 1284 patients. Thirty-four of 1304 patients with available data died during the in-hospital period (Table 3), yielding an overall in-hospital mortality rate of $2.6 \% \pm 0.1 \%$. Within the 30 -day period, there were no additional deaths, yielding a 30 -day (operative) mortality rate of $2.6 \% \pm 0.1 \%$.

\section{Follow-up Data}

Patients were examined 1, 3, 6, 12, 24, and 60 months after discharge with computed tomographic scanning. The major parameters for the follow-up period have included false luminal thrombosis, morphous of stent, type I endoleak, and organ or peripheral arterial blood supply. Follow-up information was available for all 1304 patients (Table 4). The time to follow-up (27.1 \pm 17.5 months) was available for only 1151 patients. False lumen thrombosis was reported in $92.9 \% \pm 0.5 \%$ of the patients (Table 4 ). Late surgical conversion was performed in $0.8 \% \pm 0.1 \%$ of the patients, and adjunctive endovascular stent graft procedures were performed in $1.6 \% \pm 0.1 \%$ of the patients. Therefore the total reintervention rate was $2.4 \% \pm 0.1 \%$ over the follow-up period of $27.1 \pm 17.5$ months.

Aortic rupture occurred in $0.5 \% \pm 0.0 \%$ of the patients during the follow-up period. A total of $1.5 \% \pm 0.1 \%$ of the patients died during the follow-up period. Figure E1 shows survival rates for all patients in whom the exact time to death was available in life-table format. Specifically, the survival rates were $96.9 \%$ at 30 days, $96.7 \%$ at 6 months, $96.4 \%$ at 1 year, $95.6 \%$ at 2 years, and $95.2 \%$ at 5 years.
TABLE 3. In-hospital data

\begin{tabular}{lrc}
\hline & $\begin{array}{c}\text { Data } \\
\text { available (n) }\end{array}$ & No. of events \\
\hline Procedure success & 1301 & $1290(99.2 \% \pm 0.1 \%)$ \\
No. of stent grafts per patient & 656 & 1.1 \\
Surgical conversion & 1304 & $9(0.7 \% \pm 0.1 \%)$ \\
Adjunctive endovascular & 1304 & $16(1.2 \% \pm 0.2 \%)$ \\
$\quad$ procedures & & \\
Overall complications & 1284 & $57(4.4 \% \pm 0.2 \%)$ \\
Major complications & 1284 & $44(3.4 \% \pm 0.1 \%)$ \\
Minor complications & 1284 & $13(1.0 \% \pm 0.1 \%)$ \\
Procedure-related complications & 1301 & $25(1.9 \% \pm 0.1 \%)$ \\
$\quad$ Retrograde type A AD & 1301 & $5(0.4 \% \pm 0.0 \%)$ \\
$\quad$ Access complications & 1301 & $5(0.4 \% \pm 0.0 \%)$ \\
Neurologic complications & 1284 & $8(0.6 \% \pm 0.0 \%)$ \\
$\quad$ Stroke & 1284 & $3(0.2 \% \pm 0.0 \%)$ \\
$\quad$ Paraplegia & 1284 & $0 \%$ \\
In-hospital mortality & 1304 & $34(2.6 \% \pm 0.1 \%)$ \\
In-hospital mortality, procedure & 1304 & $10(0.8 \% \pm 0.0 \%)$ \\
$\quad$ related & & \\
In-hospital mortality, non-procedure & 1304 & $21(1.6 \% \pm 0.1 \%)$ \\
$\quad$ related & & \\
$30-\mathrm{d}$ mortality & 1304 & $34(2.6 \% \pm 0.1 \%)$ \\
\hline$A D$, Aortic dissection. & &
\end{tabular}

\section{Results of Stent Graft Placement in Relation to Publication Date}

Reported technical success rates were lower in the early studies published between 2001 and $2004(94.7 \% \pm$ $0.7 \%$ ) when compared with the more recent studies published between 2005 and $2007(99.6 \% \pm 0.0 \%, P<.001$, Table 5). The overall rate of complications was consistently higher in the earlier studies $(11.4 \% \pm 1.6 \%$ vs $3.8 \% \pm$ $0.1 \%, P<.001)$. However, the rate of neurologic complications, in particular, was lower in comparison with that seen in the more recent studies $(0 \%$ vs $0.7 \pm 0.0 \%, P<.001)$. No significant difference was identified in operative or 1-year mortality between the 2 groups (Table 5).

\section{Influence of Operator's Experience}

As shown in Table 6, centers with a total number of patients beyond the median had a better procedural success

TABLE 4. Follow-up data over $27.1 \pm \mathbf{1 7 . 5}$ months after stent graft placement

\begin{tabular}{lcc}
\hline & $\begin{array}{c}\text { Data } \\
\text { available (n) }\end{array}$ & No. of events (n) \\
\hline Duration of follow-up (mo) & 1151 & $27.1 \pm 17.5$ \\
False lumen thrombosis & 1037 & $963(92.9 \% \pm 0.5 \%)$ \\
Late surgical conversion & 1045 & $8(0.8 \% \pm 0.1 \%)$ \\
Adjunctive endovascular & 1062 & $17(1.6 \% \pm 0.1 \%)$ \\
$\quad$ procedures & & \\
Late complications & 1062 & $38(3.6 \% \pm 0.1 \%)$ \\
Late mortality & 1033 & $15(1.5 \% \pm 0.1 \%)$ \\
\hline
\end{tabular}


TABLE 5. Results of stent graft placement in relation to publication date

\begin{tabular}{|c|c|c|c|c|c|}
\hline & \multicolumn{4}{|c|}{ Data available (n) } & \multirow[b]{2}{*}{$P$ valu } \\
\hline & \multicolumn{2}{|c|}{ Publication date, 2001-2004 $(\mathrm{n}=114)$} & \multicolumn{2}{|c|}{ Publication date, 2005-2007 $(n=1187)$} & \\
\hline No. of publications & & 10 & & 29 & - \\
\hline Patients/center (median) & & $10.5(5-20)$ & & $22(4-180)$ & - \\
\hline Procedural success & 114 & $94.7 \% \pm 0.7 \%$ & 1187 & $99.6 \% \pm 0.0 \%$ & $<.001$ \\
\hline Overall complications & 114 & $11.4 \% \pm 1.6 \%$ & 1170 & $3.8 \% \pm 0.1 \%$ & $<.001$ \\
\hline Neurologic complications & 114 & $0 \%$ & 1170 & $0.7 \% \pm 0.0 \%$ & $<.001$ \\
\hline 30-d Mortality & 114 & $3.5 \% \pm 0.5 \%$ & 1187 & $2.5 \% \pm 0.1 \%$ & $.516^{*}$ \\
\hline 1-y Survival & 63 & $96.8 \% \pm 0.9 \%$ & 970 & $96.3 \% \pm 0.1 \%$ & $.895^{*}$ \\
\hline
\end{tabular}

*Log-rank test.

rate and lower rates of complications and mortality than centers with low numbers of treated patients $(98.4 \% \pm 0.4 \%$ vs $99.3 \% \pm 0.1 \%$ in procedural success rate, $P<.001 ; 5.9 \% \pm$ $0.9 \%$ vs $4.2 \% \pm 0.1 \%$ in overall complications, $P=.01$; and $3.2 \% \pm 0.5 \%$ vs $2.5 \% \pm 0.1 \%$ in 30 -day mortality rate, $P<.001)$. However, the rate of neurologic complications was higher in the centers with a total number of patients beyond the median $(0.7 \% \pm 0.0 \%$ vs $0 \%, P<.001$, Table 6).

\section{Procedure-Related Versus Non-Procedure-Related Mortalities}

Figure E2 depicts the procedure-related and non-procedure-related mortalities over the 30-day treatment period after the patients were accepted. Non-procedure-related mortality was higher than procedure-related mortality $(1.8 \% \pm 0.1 \%$ vs $0.8 \% \pm 0.0 \%, P=.016)$.

\section{DISCUSSION}

In this retrospective study we evaluated, by means of a large-scale meta-analysis, the efficacy of endovascular stent graft treatment for type B AD in China. Although the traditional antihypertensive therapy remains the first-line treatment for type B AD, endovascular stent graft placement is gaining more and more attention, especially with the high technical success rate and improved morbidity and mortality compared with those seen with its surgical counterpart. ${ }^{8,46}$ The concept of endovascular stent graft placement was propelled by the desire to induce aortic remodeling by means of exclusion of the false lumen and thrombosis of the false lumen and, at the same time, avoiding the risks associated with open surgical intervention. Clinical studies have suggested that patients with type B AD undergoing endovascular stent graft placement have a better midterm prognosis than those receiving antihypertensive medicine or undergoing traditional open surgical intervention. ${ }^{47}$ For instance, Nienaber and colleagues ${ }^{4}$ showed that in comparison with the traditional surgical treatment, stent grafting had a lower perioperative mortality $(0 \%$ vs $8 \%$ for surgical treatment), lower mortality after 30 days $(0 \%$ vs $8 \%$ ), and lower mortality after 1 year $(0 \%$ vs $33 \%)$ in patients with subacute or chronic type B AD. Similarly, the Investigation of Stent Grafts in Patients with Type B Aortic Dissection trial in Europe showed that treatment of uncomplicated AD by means of stent grafting plus antihypertensive medications has a 1-year survival rate of $95 \%$ in contrast to $77 \%$ for patients receiving antihypertensive treatment alone. ${ }^{8}$ In addition, the European Collaborators on Stent Graft Techniques for Thoracic Aortic Aneurysm and Dissection (EUROSTAR) study showed that for 131 patients with AD (57\% with complicated $\mathrm{AD}$ and $43 \%$ with uncomplicated $\mathrm{AD}$ ) treated by means of endovascular stent grafting, the primary technical success was $89 \%$, and paraplegia occurred in just $0.8 \%$ of patients. The outcome at 1 year was more favorable for stent treatment with regard to aortic expansion $(0 \%)$ and late survival $(90 \%))^{48}$

Our study analyzed 1304 patients with type B dissection who underwent endovascular stent graft placement between 2001 and 2007 in China and demonstrated that endovascular stent graft treatment of AD was performed with a technical success rate of greater than $99 \%$. Furthermore, our data

TABLE 6. Influence of endovascular experience

\begin{tabular}{|c|c|c|c|c|c|}
\hline & \multicolumn{4}{|c|}{ Data available (n) } & \multirow[b]{2}{*}{$P$ value } \\
\hline & \multicolumn{2}{|c|}{ Endovascular experience, $\leq 16$ patients $(n=188)$} & \multicolumn{2}{|c|}{ Endovascular experience, $>16$ patients $(n=1113)$} & \\
\hline No. of publications & & 20 & & 19 & - \\
\hline Patients/center (median) & & $9.5(4-16)$ & & $34(17-180)$ & - \\
\hline Procedural success & 188 & $98.4 \% \pm 0.4 \%$ & 1113 & $99.3 \% \pm 0.1 \%$ & $<.001$ \\
\hline Overall complications & 188 & $5.9 \% \pm 0.9 \%$ & 1096 & $4.2 \% \pm 0.1 \%$ & .01 \\
\hline Neurologic complications & 188 & $0 \%$ & 1096 & $0.7 \% \pm 0.0 \%$ & $<.001$ \\
\hline 30-d Mortality & 188 & $3.2 \% \pm 0.5 \%$ & 1113 & $2.5 \% \pm 0.1 \%$ & $<.001 *$ \\
\hline 1-y Survival & 130 & $93.9 \% \pm 0.8 \%$ & 903 & $96.7 \% \pm 0.1 \%$ & $.198 *$ \\
\hline
\end{tabular}

*Log-rank test. 
showed an acute survival rate of $97.4 \%$ after stent graft placement, which is comparable with the reported survival rates after medical or surgical treatment of type B AD. For example, Dake and associates ${ }^{49}$ showed that stent grafting was associated with a $16 \%$ mortality within 30 days in patients with acute-type $\mathrm{AD}$ who had life-threatening complications. This figure for the same category of patients treated conventionally with an emergency surgical procedure is approximately $40 \%$ and as high as $70 \%$ for patients treated with drugs. ${ }^{49-51}$ In addition, Hagan and colleagues ${ }^{52}$ showed $31.4 \%$ and $10.7 \%$ of in-hospital mortalities for acute type B AD managed surgically and medically, respectively. Although our study and others support the idea that stent grafting is the optimal treatment for elective cases of type $\mathrm{B} A D$ in terms of acute and midterm survival rates, one should be extremely careful in drawing any conclusions without a randomized direct comparison with drug or surgical treatment strategies because patient selection might differ. Nevertheless, drug therapy is still the first-line treatment for type B $\mathrm{AD}$, and stent grafting might have the potential to replace or supplement drug therapy.

In comparison with the study by Eggebrecht and colleagues, ${ }^{2}$ our study of the Chinese-language literature suggests favorable rates of technical success, major complications, and improved acute and midterm survival. This might be because, first of all, the average age for patients with type $\mathrm{B} A D$ in our study is 10 years younger than that in the patients in the study by Eggebrecht and colleagues. In addition, some risk factors are much lower in our study than those in the study by Eggebrecht and colleagues. For example, the rate of acute dissection is $36.7 \% \pm 1.0 \%$ in our study compared with $58.1 \% \pm 1.8 \%$ in the study by Eggebrecht and colleagues. The rate of rupture dissection is $2.0 \% \pm 0.2 \%$ in our study compared with $16.1 \% \pm 1.2 \%$ in the study by Eggebrecht and colleagues. These risk factors have an effect on the patient's ability to tolerate the treatment and consequently have an effect on the outcome.

Second, the technique of stent grafting was applied in China 2 years after it was introduced to Europe and North America. This allowed the Chinese surgeons to have more time and chance to learn from their foreign counterparts, gaining both technical experience and the experience to assess the indications of the patients.

Third, our data reveal that this technique was being used in 4 major vascular surgery centers in China (Table 1), with more than 145 cases in each center. The patients from these 4 centers account for $48.6 \%$ of all cases $(634 / 1304)$, and the technical success rate is $99.5 \%(631 / 634)$. Because these 4 vascular surgery centers ${ }^{5-7,26}$ have a wealth of experience and that ensures that nearly half of the cases of type B dissection in our study have a high successful rate and a high early and midterm survival rate. In contrast, in the study by Eggebrecht and colleagues, ${ }^{2}$ only a single center has an experience of more than 100 cases $(20.9 \%$ [127/609]), and the other $79.1 \%$ of cases $(582 / 609)$ were scattered over 38 vascular surgery centers, with the number of cases ranging from 3 to 38 . Therefore we believe these contribute to the better success rate and the better rates of early and midterm survival in our study.

Neurologic complications, especially paraplegia, remain the most severe potential complications of stent graft placement, as for surgical repair of type B dissection. Occlusion of numerous critical intercostal arteries (Adamkiewicz artery) with stent grafts is widely believed to be responsible for the increased risk of paraplegia. ${ }^{53}$ In particular, simultaneous abdominal and thoracic aortic repair with loss of lumbar and intercostal arteries appears to pose an increased risk of spinal cord damage because of insufficient collateral circulation. ${ }^{54}$ Our analysis has shown that the overall risk of neurologic complications in patients treated with stent grafting was $0.6 \%$, with none having paraplegia. In addition, our data demonstrated that stroke occurred in $0.2 \%$ of patients after stent graft treatment, which, again, is significantly lower than reported in the study by Eggebrecht and colleagues. ${ }^{2}$ We believe that this is related to the age of the patients (52.1 years in our study vs 61.0 years in the report by Eggebrecht and colleagues) because younger patients might have a lower incidence of atherosclerosis and a relatively better circulation in the medium and small arteries. When the traffic artery or the left subclavian artery is occluded by stent grafting, other arteries can compensate for the blood supply for the spinal cord or brain, thereby reducing the incidence of paraplegia and stroke.

Although a favorable survival rate and a lower incidence of neurologic complications appear to be somewhat encouraging in these initial experiences, it should be noted that inhospital complications were encountered in $4.4 \%$ of patients and $40 \%$ of these complications were related directly to the procedure itself. Figure E2 shows a statistically significant difference between the mortality rate caused by a procedurerelated process and that caused by a non-procedure-related process during the 30-day postoperative period. However, it is interesting that we found this difference to be time related. As shown in Figure E2, this difference was not apparent within 5 days after the procedure. The tendency of procedure-related mortality curve suggests that procedurerelated mortality most frequently occurs within 5 days of the operation, whereas the difference appeared 5 to 30 days after the operation. This could be useful information for the implication analysis after surgical intervention.

Our analysis suggests that centers with an experience of more than 16 stent graft procedures had a significantly higher success rate and a lower rate of complications than less experienced centers. Our data also suggested that the technical success rates have improved over time, which is accompanied by a decrease in 30-day mortality. However, neurologic complications have increased in the more recent studies compared with the earlier studies. This could be 
explained by the fact that the indications for stent graft placement have been expanded to include some high-risk patients who are more prone to complications while the experience in endovascular stent graft treatment grows. This was also evidenced by the fact that the spectrum of acute and midterm complications has broadened to include potentially disastrous events other than paraplegia or stroke. ${ }^{55}$

Our meta-analysis highlights some other technical limitations of endovascular stent graft placement in patients with type B AD. Stent grafting failed to abolish the false lumen in $7 \%$ of patients, suggesting that it might not be a definitive treatment for type B AD. Even in the presence of a thrombosed thoracic false lumen, the distal thoracic or abdominal aorta might enlarge during follow-up. Therefore there is a continued risk for aortic rupture (about $0.5 \%$ during follow-up) after stent graft placement and a need for adjunctive stent graft placement or a need for open operations in $4 \%$ of patients over time. However, the incidence of aortic rupture and the need for repeat endovascular or surgical intervention might also be related to the progression of the disease itself and might not necessarily reflect treatment failure. This is supported by the fact that $11 \%$ to $20 \%$ and $10 \%$ to $44 \%$ of patients with type $\mathrm{B} \mathrm{AD}$ require repeated operations when treated with drugs or treated surgically, respectively. ${ }^{56,57}$

Our analysis is the first to provide an overview of the literature on endovascular stent graft placement in patients with type B AD in China. Although it is not a prospective and randomized comparison with other treatment strategies for patients with type $\mathrm{B} A \mathrm{D}$, it provides an important insight into technical success, potential advantages and complications, and survival rates. However, several unavoidable limitations exist in this study.

First, the retrospective nature of this study might lead to potential bias in data collection, which would handicap the clinical applicability of the findings. Second, in general, it is impractical to include all hospitals in all regions in China. Although we were trying to be inclusive and systematic in our approach, we could only study patients who were admitted to these tertiary care centers. Third, there might be referral bias based on the type $\mathrm{B} A \mathrm{AD}$ of these medical centers. Finally, there might be some cases of type B AD that might have been overlooked. Nevertheless, we believe that our data truly represented valuable and reliable information related to stent placement for type $\mathrm{B} \mathrm{AD}$ in China.

We thank Dr Rowan Flynn for the English-language editing and proofreading.

\section{References}

1. Kurimoto Y, Morishita K, Asai Y. Endovascular stent-graft placement for vascular failure of the thoracic aorta. Vasc Health Risk Manag. 2006;2:109-16.

2. Eggebrecht $H$, Nienaber $C$, Neuhäuser $M$, Baumgart $D$, Kische $S$, Schmermund A, et al. Endovascular stent-graft placement in aortic dissection: a meta-analysis. Eur Heart J. 2006;27:489-98.
3. Resch T, Delle M, Falkenberg M, Ivancev K, Konrad P, Larzon T, et al. Remodeling of the thoracic aorta after stent grafting of type B dissection: a Swedish multicenter study. J Cardiovasc Surg (Torino). 2006;47:503-8.

4. Nienaber CA, Fattori R, Lund G, Dieckmann C, Wolf W, von Kodolitsch Y, et al. Nonsurgical reconstruction of thoracic aortic dissection by stent-graft placement. N Engl J Med. 1999;340:1539-45.

5. Shi Y, Fu W, Wang Y, Guo D, Chen B, Jiang J, et al. Review of cases of Stanford type B aortic dissecting aneurysms treated by endovascular placement of stentgrafts. J Surg Concepts Pract. 2005;10:45-9.

6. Guo W, Gai L, Liu X, Zhang G, Liang F, Li R. The endovascular repair of aortic dissection: early clinical results of 178 cases. Chin J Surg. 2005;43: 921-5.

7. Jing Z, Feng X, Bao J, Zhao Z, Zhao J, Lu Q, et al. Endovascular stent-graft exclusion for Stanford B type aortic dissections: a report of 146 patients. Chin J Surg. 2003;41:483-6.

8. Nienaber CA, Zannetti S, Barbieri B, Kische S, Schareck W, Rehders TC, et al. INvestigation of STEnt grafts in patients with type B Aortic Dissection: design of the INSTEAD trial-a prospective, multicenter, European randomized trial. Am Heart J. 2005; 149:592-9.

9. Li X, Wang S, Wu Z, Yang J, Chen W, Zhuang W, et al. Endovascular stent-graft repair of aortic dissection. Chin J Gen Surg. 2001;10:419-22.

10. Li C, Li X, Qu W, Gao F, Cui Z. Treatment of acute descending thoracic aortic dissection with endovascular stent-grafts. Chin J Emerg Med. 2002;11:395-7.

11. Huang B, Tan D, Li C. Experience of endoluminal stent graft implantation for aortic dissection. Chin Circ J. 2002;17:217-9.

12. Wang S, Chang G, Li X, Wu Z, Li S, Hu Z, et al. Endovascular stent-graft exclusion on aortic dissection and dissecting aneurysm. Chin J Surg. 2003;41:487-90

13. Zhang X, Zhang Q, Xu K, Li H, Xiao L, Wang S, et al. Endovascular stent-graft implantation for Stanford B type thoracic aortic dissection. Chin J Med Imag Technol. 2004;20:925-8.

14. Zhang X, Chen K, Fu C, Liu C, Liu C, Huang D. Treatment of descending aortic dissection with stent-graft placement. J Pract Med Techniques. 2003;10:316-7.

15. Shu C, Wang Z, Yang Z, Jiang X, Li Q, He H. Endoluminal management of artery diseases. Chin J Modern Med. 2004;14:87-91.

16. Li H, Zhou C, Guo L, Zi J, Wang Z. Endovascular stent-graft placement for treatment of thoracic descending aortic dissections. Shandong Med J. 2004;44:1-2.

17. Wu Q, Li D, Liang W, Li C. Endovascular stent-graft placement for treatment of Stanford B type aortic dissection: report of 15 cases. J Chin Physician. 2004;6: 803-4.

18. Wang X, Zeng Q, Li D, Mao Y, Wu G, Yin A, et al. Preliminary experience of endovascular stent-graft placement for patients with aortic dissection. J Clin Cardiol (China). 2004;20:643-5.

19. Yang M, Zhang J, Chen P, Sun L, Che H, Yong J. Endovascular stent-graft exclusion in treatment of aortic dissections: report of 16 cases. Chin J Med. 2005;40: 40-1.

20. Jiang M, Lu M, Huang X, Huang Y, Lu X, Li W, et al. Effect of domestic-made stent-graft placement for the treatment of aortic diseases. Acad J Shanghai Second Med Univ. 2005;25:1160-3.

21. Su J, Han Y, Li X, He J. Endovascular repair of thoracic aortic dissection with stent-graft. J Ningxia Med Coll. 2005;27:461-2.

22. Ling Q, Wen D, Wang T, Zhao P. Endovascular repair on aortic dissecting aneurysm. J Chin Physician. 2005; 17:1334-5.

23. Shan S, Chen S, Ye F, Luo J, Zhang J, Lin S. Endovascular exclusion repair of thoracoabdominal aortic dissection and follow-up. J Clin Cardiol (China). 2005;21:657-9.

24. Bao X, Zai B, Zai S, Cao H. Experience in endoluminal treatment of aortic dissecting aneurysms. Shanxi Med J. 2005;34:172-4.

25. Yu W, Shao F, Lu Z, Wang P, Wu Y, Lu L, et al. Endovascular stent-graft repair of thoracic aortic dissections. J Pract Diagn Ther. 2006;20:758-60.

26. Yu F, Huang L, Sun L. Endovascular stent-graft placement for treatment of type B dissections. Chin Circ J. 2006;21:266-9.

27. Xu S, Huang F, Li Z, Wang X, Yang J, Cai K, et al. Endovascular repair of aortic dissection (report of 78 cases). Chin J Thorac Cardiovasc Surg. 2006; 22:149-51.

28. Wang L, Tong X, Han Z, Wang X. Endovascular stent- graft repair of descending thoracic aortic dissection. Chin J Cardiovasc Rev. 2006;4:764-5.

29. Luo J, Liu Y, Fan R, Huang W, Huang M, Li G, et al. Endovascular stent-graft exclusion for patients with DeBakey III aortic dissection. J Clin Cardiol (China). 2006;22:41-3.

30. Li J, Wang M, Liu T, Liu L, Ma Y. Endovascular exclusion for Stanford type B aortic dissections. Shandong Med J. 2006;46:63-4. 
31. Adeliai S, Xu C, Ma Y. Transluminal placement of endovascular stent-graft for the treatment of Stanford B type aortic dissections: a report of 23 cases. BME Clin Med. 2006;10:300-3.

32. Zhang Y, Dou Y, Kong J, Xu J, Sun G, Wu Y, et al. Clinical study on endovascular graft exclusion as a treatment of thoracoabdominal aortic aneurysm. J Diagn Image Interv Radiol. 2006;15:247-50.

33. Wang Q, Pan J, Yu Z, Liu H. Endovascular stent-graft placement for the treatment of descending aortic dissections by percutaneous intervention technique: report of 8 cases. Clin Intern Med. 2006;23:703-4.

34. Luo J, Xiao E, Zhou S, Yang D, Shu C, Zhou X. Endovascular graft exclusion for thoracic aortic dissections. J Clin Radiol. 2006;25:1046-50.

35. Zhao J, Liao Y, Gao S, Ma Y, Hu D. Endovascular aortic stent-graft placement for treatment of Stanford type B aortic dissection: experience of 15 cases. Radiol Pract. 2006;21:600-2.

36. Wang J, Yang D, Yan D, Yuan S, Zhang Z, Li Y. Evaluate the effect of endovascular stent-graft exclusion used in type B thoracic aortic dissection aneurysm. J Kunming Med Coll. 2006;27:88-91.

37. Tan Y, Luo C, Xu G, He Z, Zhu Z. Vascular intracavitary treatment in 15 cases with Debakey III type dissecting aneurysm of aorta. Lingnan Modern Clin Surg. 2006;6:214-6.

38. Yu C, Gao Y, Zhou W, Nie Z, Lu R, Sun Y, et al. Endovascular intervention on 15 patients with aorta disease. J Bengbu Med Coll. 2006;31:592-4.

39. Li C, Li Y, Wang Z. Aorta-left subclavian artery branched endovascular stentgraft repair for Stanford type Baortic dissection. Chin J Thorac Cardiovasc Surg. 2006;22:152-4

40. Mei Z, Jing Z, Bao J, Zhao Z, Feng X, Feng R, et al. Delayed complications after endovascular exclusion for Stanford type B aortic dissections. J Surg Concepts Pract. 2007;12:31-3.

41. Liu J, Zhang Z, Tang H, Guo Y, Guo S, Ma Z, et al. Evaluation of endovascular graft exclusion in treatment of thoracic aortic dissection aneurysm of DeBakey III using stent graft. Chin J Cardiovasc Rev. 2007;5:432-4.

42. Cao G, Wang X, Qiao H, Wang L, Zhang H. Percutaneous fenestration with endovascular stent placement in the Stanford B type aortic dissection. J Jinan Univ (Med Edit). 2007;28:418-20.

43. Hu H, Deng F, Wang X, Wu W, Jia W, Li Y. Endovascular stent-grafts exclusion for the treatment of DeBakey III type aortic dissections and thoracic aneurysm. Chin J Clin Health Care. 2007;10:23-5.

44. Dong Y, Cao W, Su H, Dong S, Jiang J. Endovascular stent-graft exclusion for the treatment of descending aortic dissection. Med J NDFNC. 2007;28:186-8.
45. Jing Q, Han Y, Wang X, Luan B, Deng J, Wang Z, et al. Endovascular repair of type B aortic dissection: a report of 46 patients. Chin J Intervent Cardiol. 2007;15: 80-3.

46. Estrera AL, Miller CC, Goodrick J, Porat EE, Achouh PE, Dhareshwar J, et al. Update on outcomes of acute type B aortic dissection. Ann Thorac Surg. 2007; 83(suppl):S842-50.

47. Erbel R, Oelert H, Meyer J, Puth M, Mohr-Katoly S, Hausmann D, et al. Effect of medical and surgical therapy on aortic dissection evaluated by transesophageal echocardiography. Implications for prognosis and therapy. The European Cooperative Study Group on Echocardiography. Circulation. 1993;87:1604-15.

48. Leurs LJ, Bell R, Degrieck Y, Thomas S, Hobo R, Lundbom J, et al. Endovascular treatment of thoracic aortic diseases: combined experience from the EUROSTAR and United Kingdom Thoracic Endograft registries. $J$ Vasc Surg. 2004;40:670-80

49. Dake MD, Kato N, Mitchell RS, Semba CP, Razavi MK, Shimono T, et al. Endovascular stentgraft placement for the treatment of acute aortic dissection. $N$ Engl J Med. 1999;340:1546-52.

50. Fann JI, Smith JA, Miller DC, Mitchell RS, Moore KA, Grunkemeier G, et al. Surgical management of aortic dissection during a 30-year period. Circulation. 1995; 92(suppl):II113-21.

51. Miller DC. Acute dissection of the descending aorta. Chest Surg Clin North Am. 1992;2:347-78

52. Hagan PG, Nienaber CA, Isselbacher EM, Bruckman D, Karavite DJ, Russman PL, et al. The International Registry of Acute Aortic Dissection (IRAD): new insights into an old disease. JAMA. 2000;283:897-903.

53. Fattori R, Napoli G, Lovato L, Grazia C, Piva T, Rocchi G, et al. Descending thoracic aortic diseases: stent-graft repair. Radiology. 2003;229:176-83.

54. Mitchell R, Miller D, Dake M, Semba C, Moore A, Sakai T. Thoracic aortic aneurysm repair with an endovascular stent-graft: the "first" generation. Ann Thorac Surg. 1999;67:1971-4.

55. Eggebrecht H, Baumgart D, Radecke K, von Birgelen C, Treichel U, Herold U, et al. Aortoesophageal fistula secondary to stent-graft repair of the thoracic aorta. J Endovasc Ther. 2004;11:161-7.

56. Umana J, Miller D, Mitchell R. What is the best treatment for patients with acute type B aortic dissections-medical, surgical, or endovascular stent-grafting? Ann Thorac Surg. 2002;74(suppl):S1840-3.

57. Bernard Y, Zimmermann H, Chocron S, Litzler J, Kastler B, Etievent J, et al. False lumen patency as a predictor of late outcome in aortic dissection. Am J Cardiol. 2001;87:1378-82. 


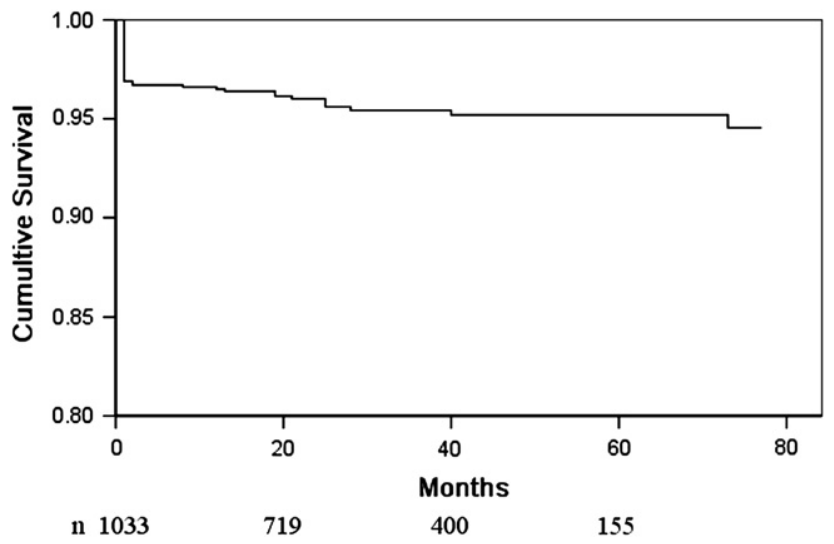

FIGURE E1. The overall survival curve of patients undergoing stent graft placement. The survival rate was generated by using the life-table nonparametric method. The available number of patients was 1033 at 1 month, 719 at 20 months, 400 at 40 months, and 155 at 60 months. Specifically, the survival rates were $96.9 \%$ at 30 days, $96.7 \%$ at 6 months, $96.4 \%$ at 1 year, $95.6 \%$ at 2 years, and $95.2 \%$ at 5 years.

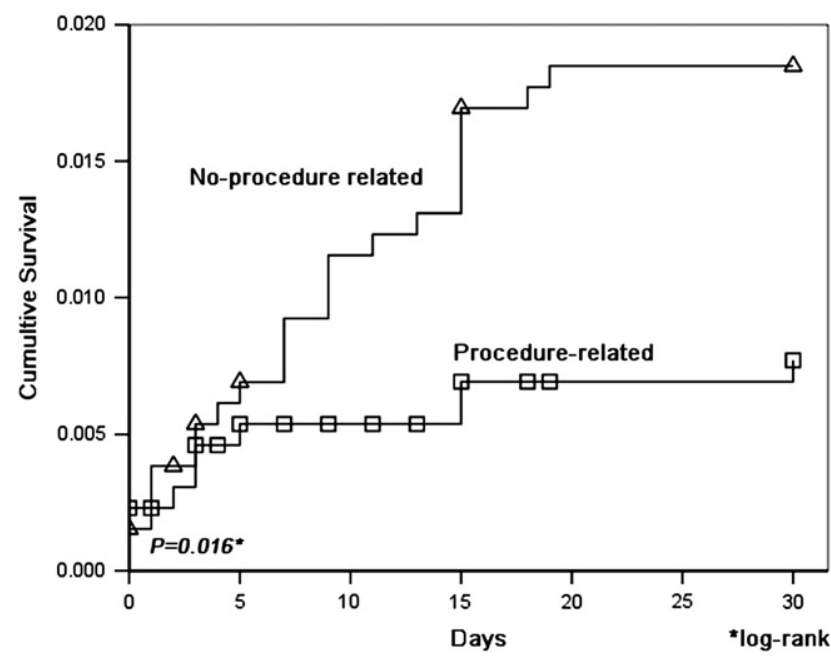

FIGURE E2. Thirty-day mortality of patients undergoing stent graft placement with procedure-related processes in comparison with those with nonprocedure related processes. The mortality data were generated by using the Kaplan-Meier method. Non-procedure-related mortality (triangles) was higher than procedure-related mortality (squares; $1.8 \% \pm 0.1 \%$ vs $0.8 \%$ $\pm 0.0 \%, P=.016)$ by using the log-rank test.

TABLE E1. Clinical characteristics, procedural data, and in-hospital and long-term outcomes of patients undergoing stent graft displacement

\section{List of variables abstracted from each article (if available)}

\section{Patient characteristics}

No. of patients with dissection

Total no. of patients reported

Age

Sex

Type of dissection

Acuity of dissection

Presence of (contained) aortic rupture

Cardiovascular risk factors

Medical comorbidities

\section{In-hospital data}

Overall complications

Major complications

Minor complications

Procedure-related complications

Retrograde type A dissection

Access complications

Myocardial complications

Renal complications

Visceral complications

Pulmonary complications

Overall neurologic complications

Paraplegia

Stroke

Need for early surgical conversion

Adjunctive endovascular procedure

Length of intensive care unit stay

Length of hospital stay

Overall in-hospital mortality

Aorta-related mortality

Non-aorta-related mortality

\section{Procedural data}

Use of general anesthesia

No. of stent grafts per patient

Stent graft diameter

Stent graft length

Procedure success

Need for emergency surgical conversion

Procedure time

Fluoroscopic time

Amount of contrast media

\section{Follow-up data}

Duration of follow-up

Need for late surgical conversion

Adjunctive endovascular procedure during follow-up Late complications

Late neurologic complications

Late retrograde type A dissection

Aortic rupture during follow-up

False lumen thrombosis

Stent migration

Shrinkage of false lumen diameter

Increase of true lumen diameter

30-d mortality

Overall late mortality during follow-up

Aorta-related late mortality

Non-aorta-related late mortality 